Review

\title{
Emerging Therapies in Pheochromocytoma and Paraganglioma: Immune Checkpoint Inhibitors in the Starting Blocks
}

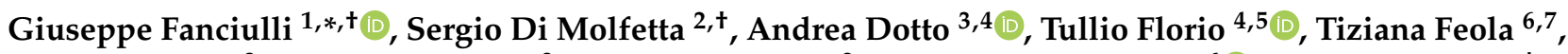 \\ Manila Rubino ${ }^{8}$, Federica de Cicco ${ }^{9}$, Annamaria Colao ${ }^{9}$, Antongiulio Faggiano ${ }^{6}$ (D) and NIKE Group $\ddagger$
}

1 NET Unit, Department of Medical, Surgical and Experimental Sciences, University of Sassari-Endocrine Unit, AOU Sassari, 07100 Sassari, Italy

2 Department of Emergency and Organ Transplantation, Section of Internal Medicine, Endocrinology, Andrology and Metabolic Diseases, University of Bari Aldo Moro, 70124 Bari, Italy; s.dimolfetta@libero.it

3 Endocrinology Unit, IRCCS Ospedale Policlinico San Martino, 16132 Genova, Italy; andreadotto91@gmail.com

4 Department of Internal Medicine, University of Genova, 16132 Genova, Italy; tullio.florio@unige.it

5 IRCCS Ospedale Policlinico San Martino, 16132 Genova, Italy

6 Department of Clinical and Molecular Medicine, Sapienza University of Rome, 00161 Rome, Italy; tiziana.feola@uniroma1.it (T.F.); antongiulio.faggiano@uniroma1.it (A.F.)

7 Neuroendocrinology, Neuromed Institute, IRCCS, 86077 Pozzilli (IS), Italy

8 Division of Gastrointestinal Medical Oncology and Neuroendocrine Tumors, European Institute of Oncology, IEO, IRCCS, 20141 Milan, Italy; manila.rubino@ieo.it

9 Department of Clinical Medicine and Surgery, Endocrinology Unit, University Federico II, 80131 Naples, Italy; deciccofederica25@gmail.com (F.d.C.); colao@unina.it (A.C.)

* Correspondence: gfanciu@uniss.it; Tel.: +39-079-264-4776

+ G Fanciulli and S Di Molfetta are joint first authors.

$\ddagger$ Membership of NIKE Group is provided in the Acknowledgments.

Citation: Fanciulli, G.; Di Molfetta, S.; Dotto, A.; Florio, T.; Feola, T.; Rubino, M.; de Cicco, F.; Colao, A.; Faggiano, A.; NIKE Group Emerging Therapies in Pheochromocytoma and Paraganglioma: Immune Checkpoint Inhibitors in the Starting Blocks. J. Clin. Med. 2021, 10, 88. https://doi.org/10.3390/jcm10010088

Received: 28 November 2020 Accepted: 25 December 2020 Published: 29 December 2020

Publisher's Note: MDPI stays neutral with regard to jurisdictional claims in published maps and institutional affiliations.

Copyright: (c) 2020 by the authors. Licensee MDPI, Basel, Switzerland. This article is an open access article distributed under the terms and conditions of the Creative Commons Attribution (CC BY) license (https: / / creativecommons.org/ licenses/by/4.0/).

\begin{abstract}
Pheochromocytoma and paraganglioma are neuroendocrine neoplasms, originating in the adrenal medulla and in parasympathetic and sympathetic autonomic nervous system ganglia, respectively. They usually present as localized tumours curable with surgery. However, these tumours may exhibit heterogeneous clinical course, ranging from no/minimal progression to aggressive (progressive/metastatic) behavior. For this setting of patients, current therapies are unsatisfactory. Immune checkpoint inhibitors have shown outstanding results for several types of solid cancers. We therefore aimed to summarize and discuss available data on efficacy and safety of current FDA-approved immune checkpoint inhibitors in patients with pheochromocytoma and paraganglioma. After an extensive search, we found 15 useful data sources (four full-published articles, four supplements of scientific journals, seven ongoing registered clinical trials). The data we detected, even with the limit of the small number of patients treated, make a great expectation on the therapeutic use of immune checkpoint inhibitors. Besides, the newly detected predictors of response will (hopefully) be of great helps in selecting the subset of patients that might benefit the most from this class of drugs. Finally, new trials are in the starting blocks, and they are expected to shed in the next future new light on a therapy, which is considered a milestone in oncology.
\end{abstract}

Keywords: pheochromocytoma; paraganglioma; immune checkpoint inhibitors; avelumab; atezolizumab; ipilimumab; nivolumab; pembrolizumab; cemiplimab; durvalumab

\section{Introduction}

Pheochromocytoma (PHEO) and paraganglioma (PGL) are neuroendocrine neoplasms (NENs), originating in the adrenal medulla and in parasympathetic and sympathetic autonomic nervous system ganglia, respectively.

Most patients with PHEO and PGL present with localized tumours that are curable with surgery. However, these tumours exhibit heterogeneous clinical course, ranging from 
no/minimal progression to aggressive (progressive/metastatic) behavior, [1], with high morbidity and mortality rates [2].

For this subgroup of patients, several therapeutic strategies for control of tumour burden have been evaluated, and/or clinical trials are ongoing.

Therapeutic options include radionuclide therapy, such as 131-iodinemetaiodobenzylguanidine (MIBG) [3]; iobenguane, a high-specific activity preparation of 131-ioidineMIBG, that is the first and only therapy approved by FDA for patients with locally advanced or metastatic PHEO/PGL [4]; peptide receptor radionuclide therapy (i.e., somatostatin analogs labeled with 177-lutetium or 90-yttrium) [5], and chemotherapy (i.e., cyclophosphamide, vincristine, and dacarbazine) [6]. Some favorable results have also been obtained with somatostatin analogues [7], temozolomide [8], sunitinib [9], and everolimus [10].

In recent years, immunotherapy has provided promise for revolutionizing cancer treatment through the implementation of new approaches that enhance the body's natural antitumour defenses.

Although the immune system actively participates in the control of tumour development and growth through adaptive and immune responses that favor the elimination of neoplastic cells, with time tumour cells acquire the capacity to escape immune surveillance. This process, named cancer immunoediting [11], involves the selection of subpopulations of tumour cells able to directly inhibit immune cell activity allowing tumour mass to grow. Among the different mechanisms responsible of the tumour-mediated immunosuppression, the modulation of immune checkpoint protein activity is nowadays considered central to tumour immune evasion, and, consequently a major pharmacological target [12].

Immune system ability to recognize and eliminate potential noxious situations, including tumour cells, requires the activation of T cells. In particular, during tumour development, immune response is activated by the binding of T-cell receptor (TCR), expressed by $\mathrm{T}$ cells, and tumour associated antigens (TAA) within MHC molecules, via the activity of antigen-presenting cells (APCs), such as dendritic cells. This initial T lymphocyte activation mainly occurs within lymph nodes, during the first phase of the T cell-mediated immune response (priming). However, $\mathrm{T}$ cell activation after antigen binding requires the induction of a second signaling pathway mediated by the interaction of B7-1 and B7-2 ligands (also known as CD80 and CD86), expressed by APCs, and the CD28 co-receptor, expressed on T cells. This interaction induces T cell proliferation but, if it is blocked during TCR activation, $\mathrm{T}$ cells undergo to inactivation and, ultimately, apoptosis. This represents a first immune checkpoint since, to avoid immune cells overstimulation, CD28 binding to B7-1 or B7-2 can be antagonized by the interaction with cytotoxic T lymphocyte antigen-4 (CTLA-4) expressed by lymphocytes [13]. The absence of the CD28 signaling caused by CTLA-4 binding leads to T cell anergy. In cancer, CTLA-4 expression is induced in T cells after TCR activation and its signaling starts when APCs migrate from cancer to draining lymph nodes, here presenting the tumour-associated antigen to T lymphocytes, replacing CD28 by the interaction with B7 ligands [14]. Importantly, besides activated T cells, CLTA-4 is also expressed on regulatory T-cells contributing to the inhibition of the antitumour immune response. On this premises, CTLA-4 blockade was proposed as novel anticancer immunotherapy [15].

A second immune checkpoint, involving programmed cell death-1 (PD-1) inhibitory signals, was subsequently discovered in peripheral tissues [16], and relevant to the antitumour response suppression, in cells composing tumour microenvironment. PD-1 is mainly expressed on effector T lymphocytes, but can also be detected in NK cells. Its binding by two ligands (programmed death-ligand-1, PD-L1; programmed death-ligand-2, PD-L2) inhibits activation signals in T cells. Physiologically this response is considered a way to modulate immune response preventing autoimmunity. PD-L1 (also known as B7-H1) is expressed by diverse cell types, including neurons and astrocytes, endothelial/epithelial cells, and pancreatic islet cells, while PD-L2 is more confined to APCs. The immunosuppressive role of PD-1 signaling was also demonstrated by its overexpression in exhausted T 
lymphocytes, a state of functional unresponsiveness of $\mathrm{T}$ cells, that occur after sustained activation, for example in cancer patients [17].

As far as cancer cells, overexpression of PD-L1 is commonly observed both in primary tumours and in metastatic tissues, and its interaction with PD-1 leads to memory T cells inhibition [18]. Consequently, it was proposed that the blockade of PD-1/PD-L1 interaction could be a means to induce the reacquisition of antitumour activity by $\mathrm{T}$ cells. Moreover, PD-L1 was also reported to interact with B7-1, further potentiating its immunosuppressive activity [19].

To date, several antibodies have been developed to interfere with both immune checkpoints, and approved for the treatment of several solid tumours. In particular, ipilimumab is an anti-CTLA-4 antibody, nivolumab, pembrolizumab and cemiplimab are anti PD-1 antibodies, and avelumab, atezolizumab, and durvalumab are anti PD-L1 antibodies (Figure 1).

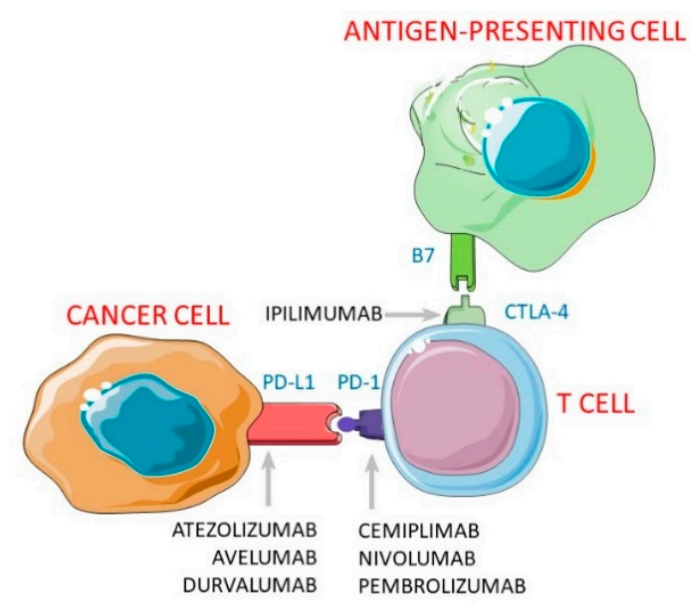

Figure 1. Molecular targets of Immune Checkpoint Inhibitors. Legend: PD-1: Programmed Cell Death-1; PD-L1: Programmed Death-Ligand-1; CTLA-4: Cytotoxic T Lymphocyte Antigen-4.

In 2017, Pinato et al. have for the first time reported the programmed cell death ligands expression in PHEOs/PGLs with a distinctive prognostic, clinic-pathologic and immuno-biologic role, thus suggesting a potential therapeutic role for PD-1/PD-L1 targeted checkpoint inhibitors in these tumours [20].

\section{Aim of the Study}

The aim of this review is to summarize and discuss available data on efficacy and safety of current FDA-approved immune checkpoint inhibitors (ICIs) in patients with $\mathrm{PHEO} / \mathrm{PGL}$.

List of drugs:

(1) Avelumab;

(2) Atezolizumab;

(3) Ipilimumab;

(4) Nivolumab;

(5) Pembrolizumab;

(6) Cemiplimab;

(7) Durvalumab.

Pharmacokinetic properties of ICIs are summarized in Table 1. 
Table 1. Pharmacokinetic properties of Immune Checkpoint Inhibitors.

\begin{tabular}{|c|c|c|c|c|c|c|}
\hline Molecule & $\begin{array}{l}\text { Commercial } \\
\text { Name } \\
\text { (FDA Approval) }\end{array}$ & Target & $\begin{array}{l}\text { Antibody } \\
\text { Description }\end{array}$ & $\begin{array}{c}\text { Relevant } \\
\text { Pharmacokinetic Parameters }\end{array}$ & $\begin{array}{c}\text { Posology } \\
\text { for Approved Indications }\end{array}$ & Notes \\
\hline Avelumab & $\begin{array}{c}\text { Bavencio } \\
\text { (March 2017) }\end{array}$ & $\begin{array}{l}\text { Programmed death } \\
\text { receptor ligand-1 } \\
\text { (PD-L1) }\end{array}$ & $\begin{array}{c}\text { Fully human monoclonal } \\
\text { antibody (IgG1-lambda), } \\
\text { developed by Merck }\end{array}$ & $\begin{array}{l}\text { Steady state reached after } 4-6 \text { weeks } \\
(2-3 \text { cycles); volume of distribution } \\
\text { is } 4.72 \mathrm{~L} \text {. Terminal half-life is } \\
\text { approximately } 6.1 \text { days in patients } \\
\text { receiving } 10 \mathrm{mg} / \mathrm{Kg} \text {. Total systemic } \\
\text { clearence } 0.59 \mathrm{~L} / \text { day }\end{array}$ & $\begin{array}{l}\text { In monotherapy, it is administered } \\
\text { e.v.at the dose of } 800 \mathrm{mg} \text {, as slow } \\
\text { infusion }(60 \mathrm{~min}) \text { every } 2 \text { weeks }\end{array}$ & $\begin{array}{l}\text { Premedication with } \\
\text { antihistamine drugs and } \\
\text { acetaminophen is } \\
\text { required for the first } \\
4 \text { weeks of treatment. }\end{array}$ \\
\hline Atezolizumab & $\begin{array}{c}\text { Tecentriq } \\
\text { (October 2016) }\end{array}$ & $\begin{array}{l}\text { Programmed death } \\
\text { receptor ligand-1 } \\
\text { (PD-L1) }\end{array}$ & $\begin{array}{c}\text { Humanized monoclonal } \\
\text { antibody (IgG1-kappa), } \\
\text { developed by } \\
\text { Hoffmann-La Roche AG }\end{array}$ & $\begin{array}{l}\text { Steady state reached after } 6-9 \text { weeks. } \\
\text { Volume of distribution is } 6.91 \mathrm{~L} \text {. The } \\
\text { half life of atezolizumab is } 27 \text { days. } \\
\text { Total systemic clearence } 0.2 \mathrm{~L} / \text { day }\end{array}$ & $\begin{array}{l}\text { It is admininistered e.v. at the } \\
\text { dose of } 840 \mathrm{mg} \text { / every two weeks }\end{array}$ & $\begin{array}{l}\text { Expression of PD-L1 } \\
(>0.1 \%) \text { has to be } \\
\text { demontrated before } \\
\text { starting the therapy }\end{array}$ \\
\hline Ipilimumab & $\begin{array}{c}\text { Yervoy } \\
\text { (March 2011) }\end{array}$ & $\begin{array}{c}\text { Cytotoxic T } \\
\text { lymphocyte antigen-4 } \\
\text { (CTLA-4) }\end{array}$ & $\begin{array}{l}\text { Fully human monoclonal } \\
\text { antibody (IgG1-kappa), } \\
\text { developed by } \\
\text { Bristol-Myers Squibb } \\
\text { and Medarex }\end{array}$ & $\begin{array}{l}\text { Steady state reached after } 9 \text { weeks. } \\
\text { Terminal half life of } 15.4 \text { days. Total } \\
\text { systemic clearence } 0.4 \mathrm{~L} / \text { day }\end{array}$ & $\begin{array}{c}\text { In monotherapy, it is administered } \\
\text { e.v.at the dose of } 3 \mathrm{mg} / \mathrm{kg} \text {, as slow } \\
\text { infusion ( } 90 \mathrm{~min}) \text { every } 3 \text { weeks. } 1 \\
\text { or } 3 \mathrm{mg} / \mathrm{Kg} \text { can be administered } \\
\text { in association with nivolumab } \\
(1-3 \mathrm{mg} / \mathrm{Kg})\end{array}$ & $\begin{array}{l}\text { Liver and thyroid } \\
\text { function test have to be } \\
\text { performed before } \\
\text { every administration }\end{array}$ \\
\hline Nivolumab & $\begin{array}{c}\text { Opdivo } \\
\text { (December 2014) }\end{array}$ & $\begin{array}{l}\text { Programmed death } \\
\text { receptor-1 } \\
\text { (PD-1) }\end{array}$ & $\begin{array}{l}\text { Fully human monoclonal } \\
\text { antibody (IgG4-kappa), } \\
\text { developed by Bristol } \\
\text { Myers Squibb. }\end{array}$ & $\begin{array}{l}\text { Steady state reached after } 25 \text { days. } \\
\text { Ternimal half life } 25 \text { days. Total } \\
\text { systemic clearence } 0.19 \text { L/day }\end{array}$ & $\begin{array}{l}\text { In monotherapy, it is administered } \\
\text { e.v.at the dose of } 240(480) \mathrm{mg} \text {, as } \\
\text { slow infusion ( } 30-60 \mathrm{~min}) \text { every } \\
2 \text { weeks }\end{array}$ & - \\
\hline Pembrolizumab & $\begin{array}{c}\text { Keytruda } \\
\text { (September 2014) }\end{array}$ & $\begin{array}{l}\text { Programmed death } \\
\text { receptor-1 (PD-1) }\end{array}$ & $\begin{array}{l}\text { Humanized monoclonal } \\
\text { antibody (IgG4-kappa), } \\
\text { developed by } \\
\text { Merck \& Co. }\end{array}$ & $\begin{array}{l}\text { Terminal half-life of pembrolizumab } \\
\text { is } 22 \text { days. Volume of distribution is } \\
\text { approximately } 6 \mathrm{~L} \text {. Clearance is } \\
0.22 \mathrm{~L} / \text { day, and proportionally } \\
\text { increases with the body weight. }\end{array}$ & $\begin{array}{l}\text { In monotherapy, it is administered } \\
\text { e.v.at the dose of } 200 \text { or } 400 \mathrm{mg} \text {, as } \\
\text { slow infusion ( } 30 \mathrm{~min} \text { ) every } \\
3 \text { weeks }\end{array}$ & $\begin{array}{l}\text { Before treatment, the } \\
\text { assessment of tumour } \\
\text { expression of PD-L1 } \\
\text { is recommended }\end{array}$ \\
\hline
\end{tabular}


Table 1. Cont.

\begin{tabular}{|c|c|c|c|c|c|c|}
\hline Molecule & $\begin{array}{l}\text { Commercial } \\
\text { Name } \\
\text { (FDA Approval) }\end{array}$ & Target & $\begin{array}{c}\text { Antibody } \\
\text { Description }\end{array}$ & $\begin{array}{c}\text { Relevant } \\
\text { Pharmacokinetic Parameters }\end{array}$ & $\begin{array}{c}\text { Posology } \\
\text { for Approved Indications }\end{array}$ & Notes \\
\hline Cemiplimab & $\begin{array}{c}\text { Libtayo } \\
\text { (September 2018) }\end{array}$ & $\begin{array}{l}\text { Programmed death } \\
\text { receptor-1 } \\
\text { (PD-1) }\end{array}$ & $\begin{array}{c}\text { Fully human monoclonal } \\
\text { antibody (IgG4-kappa), } \\
\text { developed by Regeneron } \\
\text { Pharmaceuticals }\end{array}$ & $\begin{array}{l}\text { Volume of distribution is } 5.2 \mathrm{~L} \text {. } \\
\text { Steady state clearance is } \\
\text { 0.2 L/day.The elimination half-life } \\
\text { at steady state is } 19 \text { days }\end{array}$ & $\begin{array}{c}350 \text { me every } 3 \text { weeks, as slow e.v. } \\
\text { infusion }(30 \mathrm{~min})\end{array}$ & - \\
\hline Durvalumab & $\begin{array}{l}\text { Imfinzi } \\
\text { (May 2015) }\end{array}$ & $\begin{array}{l}\text { Programmed death } \\
\text { receptor ligand-1 } \\
\text { (PD-L1) }\end{array}$ & $\begin{array}{l}\text { Fully human monoclonal } \\
\text { antibody (IgG1-kappa), } \\
\text { developed by } \\
\text { Astra.Zeneca }\end{array}$ & $\begin{array}{l}\text { Steady state is reached after } \\
16 \text { weeks. Terminal half-life of } \\
\text { durvalumab is } 18 \text { days. Volume of } \\
\text { distribution is } 5.64 \text { L. Steady state } \\
\text { clearance is } 0.2 \mathrm{~L} / \text { day. } \\
\text { Pharmacokinetics is not changed } \\
\text { when used in combination } \\
\text { with chemotherapy. }\end{array}$ & $\begin{array}{l}\text { it is administered e.v.at the dose of } \\
10 \mathrm{mg} / \mathrm{kg} \text { every } 2 \text { weeks }\end{array}$ & $\begin{array}{l}\text { PD-L1 should be } \\
\text { expressed in } \geq 1 \% \text { of } \\
\text { tumour cell }\end{array}$ \\
\hline
\end{tabular}




\section{Materials and Methods}

\subsection{Published Articles}

We performed an extensive search on PubMed, Embase, Cochrane Library, Web of Science, Scopus, by using the terms: avelumab, atezolizumab, ipilimumab, nivolumab, pembrolizumab, cemiplimab, durvalumab, paraganglioma, pheochromocytoma, neuroendocrine neoplasm, solid tumours. We additionally searched on Google Scholar in order to detect possible preliminary/partial data (published as supplement of scientific Journals). The search was last updated 23 November 2020.

\subsection{Registered Clinical Trials (RCTs)}

By using the same keywords used for the published articles, we performed an in-depth search on the following Registries: Clinical Trials Gov, EudraCT, and Chinese Clinical Trial Registry. The search was last updated 23 November 2020.

\section{Results}

\subsection{Published Articles}

We found 3254 published articles. Among them, we detected four pertinent clinical studies. We additionally found four short articles published as supplements of scientific journals.

\subsection{RCTs}

We found 952 RCTs, seven of which matched the aim of the study (treatment of $\mathrm{PHEO} / \mathrm{PGL}$ with one or more of the considered drugs). We identified one study with avelumab (Phase I, recruiting), one with atezolizumab (Phase II, recruiting), two with ipilimumab and nivolumab in combination (Phase II and Phase II, recruiting), one with nivolumab (phase I/II, recruiting), two with pembrolizumab (Phase II, recruiting and Phase I/II, recruiting). Details of the RCTs are summarized in Table 2.

\subsubsection{Avelumab}

Avelumab is a fully human, PD-L1 blocking, lambda immunoglobulin (Ig) G1 monoclonal antibody with potential antibody-dependent cell-mediated cytotoxicity [21].

The drug has been approved by FDA as a single agent for the treatment of metastatic Merkel cell carcinoma and locally advanced/metastatic urothelial carcinoma, and is also indicated as a first-line combination therapy with tyrosine kinase inhibitor axitinib in patients with advanced renal cell carcinoma [22].

Fatigue, musculoskeletal pain, diarrhea, nausea, infusion-related reaction, rash, decreased appetite, peripheral edema, and urinary tract infection were common adverse reaction (ARs) (i.e., reported in $\geq 20 \%$ of patients) when avelumab was administered as a single agent in registration trials [22]. To date, there is no published data on the efficacy and safety of avelumab in patients with PHEO/PGL.

The search on RCTs revealed 1 eligible study. NCT02923466 (Phase 1 Trial of Vesicular Stomatitis Virus Genetically Engineered to Express NIS and Human Interferon Beta (VSV-IFN $\beta$-NIS) Monotherapy and in Combination With Avelumab, in Patients With Refractory Solid Tumors) is a Phase 1 study aimed to evaluate in oncologic patients affected either by metastatic colorectal cancer, NEN or PHEO (estimated enrollment: 114 participants), the maximum tolerated dose (MTD) of VSV-IFN $\beta$-NIS (VV1) in monotherapy and in combination therapy with avelumab (only one defined outcome). According to the protocol, participants aged 18 years and older with refractory solid tumours in arm III receive avelumab intravenously every 2 weeks starting on day 1, together with VV1 either intratumourally, intravenously or both. The study started in April 2017, with the estimated study completion date being February 2021. The present study status is "Recruiting". 
Table 2. Ongoing Registered Clinical Trials.

\begin{tabular}{|c|c|c|c|c|c|c|c|c|c|}
\hline $\begin{array}{l}\text { ClinicalTrials. } \\
\text { Gov Identifier }\end{array}$ & Molecule & Trial Name & $\begin{array}{l}\text { Study } \\
\text { Phase }\end{array}$ & $\begin{array}{c}\text { Medical } \\
\text { Condition } \\
\text { under } \\
\text { Investigation }\end{array}$ & Assigned Intervention & Primary Outcome & $\begin{array}{c}\text { Estimated } \\
\text { Enrollment, } \\
n\end{array}$ & $\begin{array}{l}\text { Estimated } \\
\text { Study } \\
\text { Completion } \\
\text { Date }\end{array}$ & $\begin{array}{l}\text { Trial } \\
\text { Status }\end{array}$ \\
\hline NCT04400474 & Atezolizumab & $\begin{array}{c}\text { Exploratory Basket Trial } \\
\text { of Cabozantinib Plus } \\
\text { Atezolizumab in } \\
\text { Advanced and } \\
\text { Progressive Neoplasms } \\
\text { of the Endocrine } \\
\text { System. CABATEN } \\
\text { Study }\end{array}$ & Phase II & $\begin{array}{c}\text { Neuroendocrine } \\
\text { Tumours, } \\
\text { Anaplastic } \\
\text { Thyroid Cancer, } \\
\text { Adenocarci- } \\
\text { noma, } \\
\text { Pheochromocy- } \\
\text { toma, } \\
\text { Paraganglioma }\end{array}$ & $\begin{array}{l}\text { Combination of } \\
\text { cabozantinib } 40 \mathrm{mg}+ \\
\text { atezolizumab } 1200 \mathrm{mg} \\
\text { until disease } \\
\text { progression, } \\
\text { unacceptable toxicity or } \\
\text { patient consent } \\
\text { withdrawal }\end{array}$ & $\begin{array}{l}\text { Objective response } \\
\text { rate [Time Frame: } \\
\text { Through study } \\
\text { completion, average } \\
1 \text { year] }\end{array}$ & 144 & March 2024 & Recruiting \\
\hline
\end{tabular}


Table 2. Cont.

\begin{tabular}{|c|c|c|c|c|c|c|c|c|c|}
\hline $\begin{array}{l}\text { ClinicalTrials. } \\
\text { Gov Identifier }\end{array}$ & Molecule & Trial Name & $\begin{array}{l}\text { Study } \\
\text { Phase }\end{array}$ & $\begin{array}{c}\text { Medical } \\
\text { Condition } \\
\text { under } \\
\text { Investigation }\end{array}$ & Assigned Intervention & Primary Outcome & $\begin{array}{c}\text { Estimated } \\
\text { Enrollment, } \\
n\end{array}$ & $\begin{array}{l}\text { Estimated } \\
\text { Study } \\
\text { Completion } \\
\text { Date }\end{array}$ & $\begin{array}{l}\text { Trial } \\
\text { Status }\end{array}$ \\
\hline
\end{tabular}


Table 2. Cont.

\begin{tabular}{|c|c|c|c|c|c|c|c|c|c|}
\hline $\begin{array}{l}\text { ClinicalTrials. } \\
\text { Gov Identifier }\end{array}$ & Molecule & Trial Name & $\begin{array}{l}\text { Study } \\
\text { Phase }\end{array}$ & $\begin{array}{c}\text { Medical } \\
\text { Condition } \\
\text { under } \\
\text { Investigation }\end{array}$ & Assigned Intervention & Primary Outcome & $\begin{array}{c}\text { Estimated } \\
\text { Enrollment, } \\
n\end{array}$ & $\begin{array}{c}\text { Estimated } \\
\text { Study } \\
\text { Completion } \\
\text { Date }\end{array}$ & $\begin{array}{l}\text { Trial } \\
\text { Status }\end{array}$ \\
\hline
\end{tabular}


Table 2. Cont.

\begin{tabular}{|c|c|c|c|c|c|c|c|c|c|}
\hline $\begin{array}{l}\text { ClinicalTrials. } \\
\text { Gov Identifier }\end{array}$ & Molecule & Trial Name & $\begin{array}{l}\text { Study } \\
\text { Phase }\end{array}$ & $\begin{array}{c}\text { Medical } \\
\text { Condition } \\
\text { under } \\
\text { Investigation }\end{array}$ & Assigned Intervention & Primary Outcome & $\begin{array}{c}\text { Estimated } \\
\text { Enrollment, } \\
n\end{array}$ & $\begin{array}{c}\text { Estimated } \\
\text { Study } \\
\text { Completion } \\
\text { Date }\end{array}$ & $\begin{array}{l}\text { Trial } \\
\text { Status }\end{array}$ \\
\hline NCT02721732 & Pembrolizumab & $\begin{array}{l}\text { Phase II Study for the } \\
\text { Evaluation of Efficacy } \\
\text { of Pembrolizumab } \\
\text { (MK-3475) in Patients } \\
\text { With Rare Tumors }\end{array}$ & Phase II & $\begin{array}{l}17 \text { listed solid } \\
\text { rare tumours, } \\
\text { including ad- } \\
\text { vanced/metastatic } \\
\text { / unresectable } \\
\text { Pheochromocy- } \\
\text { toma and } \\
\text { Paraganglioma }\end{array}$ & $\begin{array}{l}\text { Pembrolizumab IV over } \\
30 \text { min on day } 1 . \\
\text { Treatment repeats every } \\
21 \text { days for up to } 24 \\
\text { months in the absence } \\
\text { of disease progression } \\
\text { or toxicity. Patients } \\
\text { with clinical response } \\
\text { or disease stabilization } \\
\text { may continue treatment } \\
\text { for up to an additional } \\
12 \text { months. }\end{array}$ & $\begin{array}{l}\text { Non-progression } \\
\text { rate (defined as the } \\
\text { proportion of } \\
\text { subjects in the } \\
\text { analysis population } \\
\text { who have no } \\
\text { progression of } \\
\text { disease) [Time } \\
\text { Frame: At } \\
27 \text { weeks] } \\
\text { Incidence of } \\
\text { adverse events } \\
\text { [Time Frame: Up to } \\
27 \text { weeks] }\end{array}$ & 225 & $\begin{array}{c}\text { Decembrer } \\
2020\end{array}$ & Recruiting \\
\hline
\end{tabular}


Table 2. Cont.

\begin{tabular}{|c|c|c|c|c|c|c|c|c|c|}
\hline $\begin{array}{l}\text { ClinicalTrials. } \\
\text { Gov Identifier }\end{array}$ & Molecule & Trial Name & $\begin{array}{l}\text { Study } \\
\text { Phase }\end{array}$ & $\begin{array}{c}\text { Medical } \\
\text { Condition } \\
\text { under } \\
\text { Investigation }\end{array}$ & Assigned Intervention & Primary Outcome & $\begin{array}{c}\text { Estimated } \\
\text { Enrollment, } \\
n\end{array}$ & $\begin{array}{l}\text { Estimated } \\
\text { Study } \\
\text { Completion } \\
\text { Date }\end{array}$ & $\begin{array}{l}\text { Trial } \\
\text { Status }\end{array}$ \\
\hline
\end{tabular}


VV1 is an oncolytic virus engineered to selectively replicate in and kill human cancer cells, in patients with refractory advanced/metastatic solid tumours, including patients with adrenal medullary tumours. Therapy with VV1 consists of two main mechanisms. First, it selectively infects, replicates in and kills cancer cells; second, the lysis of these cells cause the release of cancer immunogenic antigens, with consequent immune system's response [23]. Anti-PD-1 and anti-PD-L1 monoclonal antibodies, such as avelumab, are supposed to boost up and enhance said immune response.

Preliminary data of NCT02923466 have been recently published [24]. Among the first 18 patients with solid tumours under study, 2 (11\% of the population) had PHEO. The Authors identified the recommended VV1 dose, and compared three different VV1 infusion durations (monotherapy). No difference in safety between the three infusion durations (30, 60 and $180 \mathrm{~min}$ ) was reported, with the better anti-tumour effect (efficacy) observed with the 30-min infusion.

\subsubsection{Atezolizumab}

Atezolizumab is a humanized IgG1 kappa monoclonal antibody that selectively binds to PD-L1 and prevents its interaction with both PD-1 and B7-1 [25]. Atezolizumab has been approved by FDA as a single agent for the treatment of adult patients with locally advanced/metastatic urothelial carcinoma and metastatic non-small cell lung cancer (NSCLS), and is indicated in combination with other agents as a first-line treatment in selected patients with metastatic non-squamous NSCLC and triple-negative breast cancer [26].

Based on FDA prescribing information, fatigue, nausea, constipation, cough, dyspnea, and decreased appetite are common $(\geq 20 \%)$ ARs when atezolizumab is administered as a single agent [26].

To date, there is no published data on the efficacy and safety of atezolizumab in patients with PHEO/PGL.

The search on RCTs revealed 1 single study, named "Exploratory Basket Trial of Cabozantinib Plus Atezolizumab in Advanced and Progressive Neoplasms of the Endocrine System. CABATEN Study" (NCT04400474). This is a multi-cohort Phase 2 study aimed to evaluate, in the above mentioned population, including PHEO and PGL (estimated enrollment: 144 participants), the objective response rate (ORR, primary outcome), the adverse events (AEs), the duration of response (DoR), the progression-free survival (PFS), and the overall survival (OS) as secondary outcomes. According to the protocol, participants aged 18 years and older with advanced and progressive endocrine neoplasms receive atezolizumab $1200 \mathrm{mg}$ intravenously every three weeks (cycle), together with cabozantinib $40 \mathrm{mg}$ once daily. The study started in October 2020, with the estimated study completion date being March 2024. The present study status is "Recruiting".

\subsubsection{Ipilimumab}

Ipilimumab is a fully human IgG1 kappa monoclonal antibody that binds with high affinity and inhibits CTLA-4 [27]. As a single agent, ipilimumab is approved for the treatment of patients with unresectable/metastatic melanoma, or patients with cutaneous melanoma and pathologic involvement of regional lymph nodes who have undergone a complete resection, including total lymphadenectomy. It is also indicated in combination with nivolumab for the treatment of intermediate/poor-risk patients with previously untreated advanced renal cell carcinoma [28].

Common AR (i.e., reported in $>5 \%$ of patients) with ipilimumab as a single agent are fatigue, diarrhea, pruritus, rash, and colitis. Additional AR at high doses include nausea, vomiting, headache, weight loss, pyrexia, decreased appetite, and insomnia [28].

To date, there is no published data on the efficacy and safety of ipilimumab in patients with PHEO/PGL.

The approval of ipilimumab in combination with nivolumab for the majority of indications is linked with the proven enhanced antitumour response of the association of drugs compared with monotherapy alone in these tumours [29-31]. Ipilimumab and 
nivolumab, in fact, perform their immune checkpoint-inhibiting activity through different targets: the first one, as already said, inhibiting CTLA-4 activity, the latter blocking the interaction between PD-1 and its ligands, resulting in a complementary effect. Consistent with such evidence, currently ongoing trials evaluating ipilimumab activity for PHEO/PGL, are all designed in combination with nivolumab.

The search on RCTs revealed two eligible studies. NCT02834013 (DART: Dual AntiCTLA-4 and Anti-PD-1 Blockade in Rare Tumors) is a Phase 2 study of the combination of ipilimumab + nivolumab (arm I) vs. nivolumab alone (arm II) aimed to evaluate in patients affected by rare solid tumours, including PHEO and PGL (current estimated enrollment: 818 participants, original estimated enrollment: 334 participants), the ORR (primary outcome), the AEs, the BR, the clinical benefit rate (CBR), the OS, and the PFS (secondary outcomes). According to the protocol, participants aged 18 years and older with histologically and /or biochemically confirmed rare cancer, either in progression after at least one line of standard systemic therapy or lacking any other standard treatment proven to prolong survival, in arm 1 receive intravenous nivolumab over 30 min on days 1, 15, and 29 and intravenous ipilimumab over $60 \mathrm{~min}$ on day 1 every 42 days for up to 17 cycles, whereas in arm 2 receive only intravenous nivolumab over $30 \mathrm{~min}$ on days 1, 15, and 29. The study started in January 2017. The estimated study completion date is not given. The present study status is "Recruiting".

NCT03333616 (A Phase II Study of Nivolumab Combined With Ipilimumab for Patients With Advanced Rare Genitourinary Tumors) is a Phase 2 study aimed to evaluate in the above mentioned population, including PHEO/PGL (estimated enrollment: 57 participants), the ORR (primary outcome), the DoR, the PFS, the OS, and the AEs (secondary outcomes). According to the protocol, participants aged 18 years and older with advanced or metastatic urogenital cancer, receive intravenous nivolumab and ipilimumab every 3 weeks for a total maximum of four doses. After combination therapy, nivolumab is administered as monotherapy every 4 weeks. Doses are determined per protocol. The study started in December 2017, with the estimated study completion date being May 2025. The present study status is "Recruiting".

Very preliminary data of NCT03333616 have been recently published [32,33]: out of the 56 patients enrolled (median follow up 9.9 months, range $<1-21), 18(32.1 \%)$ were affected by adrenal tumours, but only two had PGL (3.6\%). Of these two patients, one had stable disease $(\mathrm{SD})$ and one had progressive disease (PD).

\subsubsection{Nivolumab}

Nivolumab is a fully human monoclonal antibody of IgG4 kappa isotype, which binds to the PD-1 receptor and blocks its interaction with PD-L1 and PD-L2 [34]. Nivolumab is indicated for the treatment of a number of types of cancer including melanoma (both as a monotherapy and in combination with ipilimumab), renal cell carcinoma (in combination with ipilimumab), relapsed or refractory NSCLC, classical Hodgkin lymphoma, squamous cell cancer of the head and neck, colon cancer, liver cancer, and urothelial carcinoma as monotherapy [34].

When used as a single agent in registration trials, common $(>20 \%)$ ARs were fatigue, rash, musculoskeletal pain, pruritus, diarrhea, nausea, asthenia, cough, dyspnea, constipation, decreased appetite, back pain, arthralgia, upper respiratory tract infection, pyrexia, headache, abdominal pain, and vomiting [35].

To date, there is no published data on the efficacy and safety of nivolumab in patients with PHEO/PGL.

As reported in the previous paragraph, nivolumab has been the object of study in two different RCTs in combination with ipilimumab, in order to maximize the immune checkpoint-blocking effect of the two molecules.

Regarding RCTs on nivolumab alone, the search on RCTs revealed 1 eligible study.

NCT04187404 (A Phase 1/2 Trial of a Novel Therapeutic Vaccine (EO2401) in Combination With Immune CheckPoint Blockade, for Treatment of Patients With Locally Advanced 
or Metastatic Adrenocortical Carcinoma, or Malignant Pheochromocytoma/Paraganglioma) is a Phase 1 /Phase 2 study aimed to evaluate in the above mentioned population (estimated enrollment: 72 participants), the AEs assessment (primary outcome), the OS, and the immunogenicity (secondary outcomes) of the four components that compose EO2401 (assessed by Interferon- $\gamma$ ELISpot) after therapy with an innovative cancer peptide therapeutic vaccine in combination with nivolumab. According to the protocol, participants aged 18 years and older with histologically confirmed unresectable/metastatic adrenocortical carcinoma (ACC), or unresectable malignant PHEO/PGL, are grouped in five different cohorts and receive EO2401 in combination with nivolumab at standard dose. The recommended dose of EO2401 is to be found in Cohort 1 and will be administered to the other cohorts of patients, respectively composed by previously treated ACCs, previously untreated ACCs, previously treated PHEO/PGL, and previously untreated PHEO/PGL. The study started in July 2020, with the estimated study completion date being March 2024. The present study status is "Recruiting".

The rationale of this study is based on the significant homologies existing between the TAAs and the onco-mimics, immunogenic, microbiome-derived peptides that will be administered in combination with nivolumab. As the presented antigens display high molecular homology with selected TAAs on adrenal cancer cells, a T-cell-mediated immune response is supposed to be mounted against the TAAs. Nivolumab here plays a fundamental role, permitting the adequate mounting of the T-cell response by allowing immune cell development and survival, therefore enhancing the immune cell-mediated anticancer effect.

This study is currently recruiting, but no result is available yet. Nonetheless, its conception certainly draws further attention to the possible role of immune-checkpoint blocking molecules also for the potential association with cancer peptide therapeutic vaccines.

\subsubsection{Pembrolizumab}

Pembrolizumab is a humanized monoclonal antibody of IgG4-kappa isotype that binds with high affinity to the PD-1 cell surface receptor [36]. On the basis of durable objective responses and a favorable safety profile, pembrolizumab has been approved for the treatment of melanoma, both small and NSCLS, head and neck squamous cell carcinoma, classic Hodgkin lymphoma, primary mediastinal large B-cell lymphoma, and diverse malignancies originating from either the gastrointestinal and urogenital tract [37].

In pivotal trials, common $(\geq 20 \%)$ ARs for patients taking pembrolizumab as a single agent were fatigue, musculoskeletal pain, decreased appetite, pruritus, diarrhea, nausea, rash, pyrexia, cough, dyspnea, constipation, pain, and abdominal pain [37].

Evidence supporting the use of pembrolizumab in patients with PHEO/PGL is still limited. Naing et al. first reported data from a single-center, phase 2 trial (NCT02721732, Phase II Study for the Evaluation of Efficacy of Pembrolizumab (MK-3475) in Patients With Rare Tumors) with the aim to assess the efficacy and safety profile of pembrolizumab in adults with advanced rare cancers [38]. Final results from the cohort of patients with PHEO/PGL have been recently published [39]. Indeed, 11 patients with histopathological diagnosis of non-resectable metastatic PHEO/PGL, radiographic confirmation of metastases, and disease progression for 6 months prior to study start were included in the trial and received at least one dose of the investigational drug. Pembrolizumab was administered as a single $200 \mathrm{mg}$ intravenous dose on the first day of every 21-day treatment cycle until patients either exhibited disease progression, developed unacceptable side effects, withdrew from the trial, or completed 24 months of treatment with the investigational drug.

Non-progression rate (NPR) and incidence of AEs were the primary endpoints of the trial, the first one defined as the number of patients who were alive and progression free at 27 weeks, based on immune-related RECIST (irRECIST) criteria [40]. Predefined secondary endpoints included: (i) ORR; (ii) CBR for $\geq 4$ months; (iii) PFS; (iv) OS; and (v) safety.

A single patient discontinued treatment early because of liver toxicity and was excluded from the primary (but not from secondary) endpoint analysis population. 
Accordingly, NPR was $40 \%$ (four out of 10 evaluable patients), ORR was $9 \%$ (one out of 11 patients, with partial response (PR) as their best response, BR), and CBR was 73\% (one out of 11 patients, $9 \%$, with PR; seven out of 11 patients, $64 \%$, with SD).

The median follow-up time was 17.9 months (IQR: 9.3-20.2 months). Seven patients exhibited radiographic evidence of $\mathrm{PD}$, and one other patient had clinical progression, with the median PFS being 5.7 months (95\% CI: 4.37-not reached). Six patients died because of disease progression across the trial, and the median OS was 19 months (95\% CI: 9.9-not reached).

Safety data were consistent with the established profile of the drug. Four patients had grade 3 AEs, and no patient reported an adrenergic crisis during or immediately after the infusion [39].

In the same study, in search of possible markers of response to treatment with ICIs, PD-L1 membrane expression and presence of tumour infiltrating lymphocytes (TILs) were assessed in tumour samples of 9 out of 11 patients enrolled in the trial.

PD-L1 membrane expression was evaluated by immunohistochemistry, and an $\mathrm{H}-$ score ranging from 0 to 300 was assigned. TILs within tumour nests were microscopically evaluated and scored on a scale from 0 (absence of TILs) to 3 (intense intratumoural lymphocytic infiltration).

Overall, there was no clear association between PD-L1 membrane expression and TILs in primary tumour samples and clinical or radiological response [39].

In another study, Tapia et al. assessed tumour cell content (TC) both at baseline and between days 15 and 21 of the first cycle of treatment in 57 patients with advanced rare tumours from the abovementioned phase II trial [41]. TC was estimated on hematoxylin and eosin-stained slides and tumours were dichotomized into low and high TC according to a cut-off of $10 \%$. Out of five patients with PHEO/PGL included in this analysis, four had high TC at baseline, and three had high TC on-treatment. In the total cohort, objective response was significantly associated with decrease in TC from baseline to on-treatment. However, data on the PHEO/PGL subgroup are not available.

Preliminary data on the role of radiomics in predicting RECIST-based tumour response to pembrolizumab [42] are available for 58 patients with either squamous cell carcinoma of the skin, ACC, carcinoma of unknown primary, and PGL (five patients [43]). By using selected radiomic features, the authors obtained a classification model able to distinguish between the 21 responders and the 37 non-responders of the study, with 100\% sensitivity and $95 \%$ specificity.

In late 2019, an interim analysis of a Phase I-II trial (NCT02332668) named KEYNOTE051 has been published showing that Pembrolizumab has low antitumour activity in the majority of pediatric tumour types, and PD-L1 expression per se is not sufficient as a biomarker for response to treatment in pediatric patients [44]. The trial aims at investigating $\mathrm{MTD} /$ maximum administered dose, and dose confirmation in Phase I, and evaluating the safety and efficacy (for pediatric neoplasms) in Phase II (estimated enrollment: 310 patients). The actual study start date was in March 2015 and final results of KEYNOTE 051 are expected by September, 2022. To date, a single patient with PGL, located in the central nervous system, has been enrolled in the trial and therefore subjected to administration of pembrolizumab.

The primary hypothesis of this study was that administration of Pembrolizumab in PD-L1 positive tumours would result in an ORR greater than $10 \%$ for at least one type of neoplasm. According to the initial results thus far posted (154 patients), the only pediatric tumours where pembrolizumab showed significant activity was Hodgkin Lymphoma (ORR 60.0\%). This trial was designed to include a wide variety of tumours histotypes, so that the numerousness of the groups of the same type of tumour is often low or very low. Conclusions regarding the antitumour efficacy of pembrolizumab are to be drawn considering the totality of patients, therefore no possible finding is obtainable for each subgroup, let alone the PGL one. 


\subsubsection{Cemiplimab}

Cemiplimab is a fully human monoclonal antibody of IgG4 kappa isotype that binds to the PD-1 receptor and blocks its interaction with both PD-L1 and PD-L2. Cemiplimab has been approved by FDA as a single agent for the treatment of adult patients with metastatic or locally advanced cutaneous squamous cell carcinoma who are not candidates for performing curative-intent surgery or radiation therapy. Based on drug labelling information, common $(\geq 20 \%)$ ARs for cemiplimab are fatigue, rash and diarrhea [45]. To our knowledge, neither clinical studies have been published, nor have RCTs yet been registered for cemiplimab in this subset of patients.

\subsubsection{Durvalumab}

Durvalumab is an engineered fully human, IgG1-kappa, monoclonal antibody directed against PD-L1, thus preventing its interaction with both PD-1 and CD80 [46]. The drug has been approved by FDA for the treatment of patients with locally advanced or metastatic urothelial carcinoma who had disease progression despite first-line platinumbased chemotherapy, or patients with unresectable, stage III NSCLC whose disease has not progressed following platinum-based chemotherapy and radiation therapy.

Common $(>15 \%)$ ARs in registration trials were fatigue, musculoskeletal pain, constipation, decreased appetite, nausea, peripheral edema, urinary tract infection, cough, pneumonitis/radiation pneumonitis, upper respiratory tract infections, dyspnea, rash and alopecia [47]. As for cemiplimab, we did not find any published or ongoing study finalized at evaluating the efficacy on PHEO/PGL.

\section{Discussion}

Our review shows a substantial and increasing interest in the field of treatment of aggressive (progressive/metastatic) PHEO/PGL with ICIs. Even if the full results (in term of clinical/radiological outcomes) arise from the studies with pembrolizumab, very preliminary data are coming for RCTs involving avelumab [24], and ipilimumab + nivolumab $[32,33]$.

As for pembrolizumab, the study performed by Jimenez and et al. [39] shows a $40 \%$ NPR, with a $73 \%$ of CBR, (being the $64 \%$ of SD the most frequent response), and a 19 months of OS, coupled with an acceptable safety profile. Despite the low number of subjects treated (11 patients), and the relatively short follow up (median, 17.9 months), the results appear promising, especially in view of the clinically severe status of the patients enrolled in this study, such as unresectable primary metastatic tumour, disease progression prior to enrollment, and previous treatment with chemotherapy (cyclophosphamide, vincristine, and dacarbazine, CVD), radiopharmaceuticals (MIBG), or tyrosine kinase inhibitors in $8 / 11(73 \%)$.

However, we found no head-to-head comparison to assess the efficacy of ICIs against other available therapies. Moreover, some additional points should be highlighted.

Firstly, there are a series of ongoing RCTs on both ICI-monotherapy and combination therapy that collectively involve more than 600 patients with solid tumours, including PHEO/PGLs.

Secondly, even if it is presently impossible to draw any conclusion about the antitumoural activity of ipilimumab + nivolumab in PHEO/PGL based on the preliminary results so far available, very recent data suggest the potential benefits of such a combination of drugs in other NENs [48,49]. In addition to current trials on combination therapy, potential future studies employing ICIs in sequence, or as sandwich therapy, would be crucial to further define the role if ICIs in patients with aggressive PHEO/PGL.

Thirdly, the (possible) results on NENs of RCTs employing ICIs not yet approved by FDA for human use (i.e., spartalizumab, a PD-1 inhibitor (RCT NCT03891953 and NCT04261439), and tremelimumab, a PD-1 inhibitor (RCT NCT02643303), might hopefully open new horizons in this field. 
Fourthly, the identification of potential predictors of response to ICI therapy in patients with diverse solid tumours, including PHEOs/PGLs, is underway. In addition to the above mentioned, radiomic-based predictive model [42], a recent study including 177 PHEOs/PGLs [50] identified, through the analysis of gene expression data of the primary tumours, an algorithm able to predict the positive response to ICIs. Worthy of note, PD-L1 expression by immunohistochemistry has been advocated as a putative predictive correlate of response to anti-PD-1 therapies, and incorporated as a biomarker in clinical studies [51]. Even though evidence that supports this specific hypothesis in PHEO/PGL patients still lacks, it is self-evident that the identification of putative predictors of response will bring into focus the use of ICIs in this setting.

As a final point, we should consider that PHEO/PGL patients harboring specific mutations might benefit the most from ICIs therapy. In fact, despite most of PHEOs/PGLs are classified as sporadic tumours, germline mutations were identified in about $35 \%$ of them, involving over 20 genes [52]. These mutations are classified in three clinically-relevant subgroups: pseudohypoxia, kinase signaling, and Wnt signaling [53]. The pseudohypoxia subgroup includes mutations in a highly significant number of genes, including succinate subunits A, B, C, D, fumarate hydratase, and von Hippel-Lindau tumour suppressor gene, encoding for proteins involved in the cell response induced by conditions of hypoxia. Of note, mutations in this subgroup of genes, although acting at different metabolic levels and on different substrates, ultimately cause the stabilization of the hypoxia-inducible factor (HIF). It was recently reported that increased expression of the immune checkpoint ligand PD-L1 occurs via a HIF-dependent mechanism potentiating the capacity of tumour cells and their surrounding stroma to repress T cells activity [54]. Thus, the engagement of PD-1 signaling represents a novel pathway of T-cell suppression promoted by pseudohypoxia, and provides the rational basis for a more effective use of ICIs in the specific subgroup of PHEO/PGL patients bearing the above mentioned pseudohypoxia-related gene mutations.

\section{Conclusions}

Published data make a great expectation on the therapeutic use of ICIs in aggressive (progressive/metastatic) PHEO/PGL. New trials are in the starting blocks, and this fervid activity underlines the interest of the scientific community to define the role of a therapy that has already shown outstanding results for other types of cancer.

Author Contributions: G.F., S.D.M., A.D., T.F. (Tullio Florio), T.F. (Tiziana Feola), M.R., F.d.C. were responsible for the design, the methodology, the draft preparation, the reviewing and editing. A.C. and A.F. were responsible for the supervision. All authors have read and agreed to the published version of the manuscript.

Funding: This work was supported by the Italian Ministry of Education, University and Research (MIUR): PRIN 2017Z3N3YC, and by the University of Sassari, Italy: Specialist International Clinical Training (SICT) Project.

Institutional Review Board Statement: Not applicable.

Informed Consent Statement: Not applicable.

Data Availability Statement: No new data were created or analyzed in this study. Data sharing is not applicable to this article.

Acknowledgments: This review is part of the 'Neuroendocrine Tumors Innovation Knowledge and Education' project led by Annamaria Colao and Antongiulio Faggiano, which aims at increasing the knowledge on NET. We would like to acknowledge all the Collaborators of the "NIKE" project: Manuela Albertelli-Genova; Barbara Altieri-Wurzburg; Luigi Barrea-Napoli; Filomena Bottiglieri-Napoli; Severo Campione-Napoli; Alessandra Dicitore-Milano; Diego FeroneGenova; Francesco Ferraù-Messina; Erika Grossrubatscher-Milano; Marco Gallo-Torino; Elisa Giannetta-Roma; Federica Grillo—Genova; Elia Guadagno—Napoli; Valentina Guarnotta—Palermo; Andrea M. Isidori-Roma; Andrea Lania-Milano; Andrea Lenzi-Roma; Fabio Lo Calzo-Avellino; Pasquale Malandrino-Catania; Erika Messina-Messina; Roberta Modica-Napoli; Giovanna Muscogiuri-Napoli; Genoveffa Pizza-Avellino; Luca Pes—Sassari; Riccardo Pofi-Roma; Giu- 
lia Puliani-Roma; Carmen Rainone-Napoli; Paola Razzore-Torino; Laura Rizza-Roma; Rosa Maria Ruggieri-Messina; Emilia Sbardella-Roma; Franz Sesti-Roma; Mary Anna Venneri-Roma; Giovanni Vitale-Milano; Maria Chiara Zatelli-Ferrara.

Conflicts of Interest: All authors declare no conflict of interest. The funders had no role in the design of the study; in the collection, analyses, or interpretation of data; in the writing of the manuscript, or in the decision to publish the results.

\begin{abstract}
Abbreviations
AE: Adverse Event; AR: Adverse Reaction; APC: Antigen-Presenting Cell; BR: Best Response; CBR: Clinical Benefit rate; CTLA-4: Cytotoxic T Lymphocyte Antigen-4; DoR: Duration of Response; HIF: Hypoxia-Inducible Factor; ICI: Immune Checkpoint Inhibitor; MCH: Major Histocompatibility Complex; MTD: Maximum Tolerated Dose; MIBG: Metaiodobenzylguanidine; NPR: Non-Progression Rate; NEN: Neuroendocrine Neoplasm; NSCLS: Non-Small Cell Lung Cancer; ORR: Objective Response Rate; OS: Overall Survival; PD: Progressive Disease; PD-1: Programmed Cell Death-1; PD-L1: Programmed Death-Ligand-1; PD-L2: Programmed Death-Ligand-2; PFS: Progression-Free Survival; PGL: Paraganglioma; PHEO: Pheochromocytoma; PR: Partial Response; RCT: Registered Clinical Trial; SD: Stable Disease; TAA: Tumour-Associated Antigen; TCR: T-Cell Receptor; TIL: Tumour Infiltrating Lymphocyte; VV1: VSV-IFN $\beta$-NIS.
\end{abstract}

\title{
References
}

1. Jimenez, C.; Rohren, E.; Habra, M.A.; Rich, T.; Jimenez, P.; Ayala-Ramirez, M.; Baudin, E. Current and Future Treatments for Malignant Pheochromocytoma and Sympathetic Paraganglioma. Curr. Oncol. Rep. 2013, 15, 356-371. [CrossRef] [PubMed]

2. Jasim, S.; Jimenez, C. Metastatic Pheochromocytoma and Paraganglioma: Management of Endocrine Manifestations, Surgery and Ablative Procedures, and Systemic Therapies. Best Pract. Res. Clin. Endocrinol. Metab. 2020, 34, 101354. [CrossRef] [PubMed]

3. Van Hulsteijn, L.T.; Niemeijer, N.D.; Dekkers, O.M.; Corssmit, E.P.M. (131)I-MIBG Therapy for Malignant Paraganglioma and Phaeochromocytoma: Systematic Review and Meta-Analysis. Clin. Endocrinol. 2014, 80, 487-501. [CrossRef] [PubMed]

4. FDA. Fast Track Approvals Information. 2018. Available online: https://www.fda.gov/media/123571/download (accessed on 11 November 2020).

5. Forrer, F.; Riedweg, I.; Maecke, H.R.; Mueller-Brand, J. Radiolabeled DOTATOC in Patients with Advanced Paraganglioma and Pheochromocytoma. Q. J. Nucl. Med. Mol. Imaging 2008, 52, 334-340. [PubMed]

6. Grogan, R.H.; Mitmaker, E.J.; Duh, Q.-Y. Changing Paradigms in the Treatment of Malignant Pheochromocytoma. Cancer Control 2011, 18, 104-112. [CrossRef]

7. Tenenbaum, F.; Schlumberger, M.; Lumbroso, J.; Parmentier, C. Beneficial Effects of Octreotide in a Patient with a Metastatic Paraganglioma. Eur. J. Cancer 1996, 32A, 737. [CrossRef]

8. Hadoux, J.; Favier, J.; Scoazec, J.-Y.; Leboulleux, S.; Al Ghuzlan, A.; Caramella, C.; Déandreis, D.; Borget, I.; Loriot, C.; Chougnet, C.; et al. SDHB Mutations Are Associated with Response to Temozolomide in Patients with Metastatic Pheochromocytoma or Paraganglioma. Int. J. Cancer 2014, 135, 2711-2720. [CrossRef]

9. O'Kane, G.M.; Ezzat, S.; Joshua, A.M.; Bourdeau, I.; Leibowitz-Amit, R.; Olney, H.J.; Krzyzanowska, M.; Reuther, D.; Chin, S.; Wang, L.; et al. A Phase 2 Trial of Sunitinib in Patients with Progressive Paraganglioma or Pheochromocytoma: The SNIPP Trial. Br. J. Cancer 2019, 120, 1113-1119. [CrossRef]

10. Oh, D.-Y.; Kim, T.-W.; Park, Y.S.; Shin, S.J.; Shin, S.H.; Song, E.-K.; Lee, H.J.; Lee, K.-W.; Bang, Y.-J. Phase 2 Study of Everolimus Monotherapy in Patients with Nonfunctioning Neuroendocrine Tumors or Pheochromocytomas/Paragangliomas. Cancer 2012, 118, 6162-6170. [CrossRef]

11. Vesely, M.D.; Schreiber, R.D. Cancer Immunoediting: Antigens, Mechanisms and Implications to Cancer Immunotherapy. Ann. N. Y. Acad. Sci. 2013, 1284, 1-5. [CrossRef]

12. Franzin, R.; Netti, G.S.; Spadaccino, F.; Porta, C.; Gesualdo, L.; Stallone, G.; Castellano, G.; Ranieri, E. The Use of Immune Checkpoint Inhibitors in Oncology and the Occurrence of AKI: Where Do We Stand? Front Immunol. 2020, 11, 574271. [CrossRef] [PubMed]

13. Brunet, J.F.; Denizot, F.; Luciani, M.F.; Roux-Dosseto, M.; Suzan, M.; Mattei, M.G.; Golstein, P. A New Member of the Immunoglobulin Superfamily-CTLA-4. Nature 1987, 328, 267-270. [CrossRef] [PubMed]

14. Linsley, P.S.; Golstein, P. Lymphocyte Activation: T-Cell Regulation by CTLA-4. Curr. Biol. 1996, 6, 398-400. [CrossRef]

15. Leach, D.R.; Krummel, M.F.; Allison, J.P. Enhancement of Antitumor Immunity by CTLA-4 Blockade. Science 1996, $271,1734-1736$. [CrossRef] [PubMed]

16. Francisco, L.M.; Sage, P.T.; Sharpe, A.H. The PD-1 Pathway in Tolerance and Autoimmunity. Immunol. Rev. 2010, 236, 219-242. [CrossRef]

17. Wherry, E.J. T Cell Exhaustion. Nat. Immunol. 2011, 12, 492-499. [CrossRef]

18. Cha, J.-H.; Chan, L.-C.; Li, C.-W.; Hsu, J.L.; Hung, M.-C. Mechanisms Controlling PD-L1 Expression in Cancer. Mol. Cell 2019, 76, 359-370. [CrossRef]

19. Butte, M.J.; Keir, M.E.; Phamduy, T.B.; Sharpe, A.H.; Freeman, G.J. Programmed Death-1 Ligand 1 Interacts Specifically with the B7-1 Costimulatory Molecule to Inhibit T Cell Responses. Immunity 2007, 27, 111-122. [CrossRef] 
20. Pinato, D.J.; Black, J.R.; Trousil, S.; Dina, R.E.; Trivedi, P.; Mauri, F.A.; Sharma, R. Programmed Cell Death Ligands Expression in Phaeochromocytomas and Paragangliomas: Relationship with the Hypoxic Response, Immune Evasion and Malignant Behavior. Oncoimmunology 2017, 6, e1358332. [CrossRef]

21. Boyerinas, B.; Jochems, C.; Fantini, M.; Heery, C.R.; Gulley, J.L.; Tsang, K.Y.; Schlom, J. Antibody-Dependent Cellular Cytotoxicity Activity of a Novel Anti-PD-L1 Antibody Avelumab (MSB0010718C) on Human Tumor Cells. Cancer Immunol. Res. 2015, 3, 1148-1157. [CrossRef]

22. FDA. Bavencio®. Highlights of Prescribing Information. Available online: https://www.accessdata.fda.gov/drugsatfda_docs/ label/2019/761049s006lbl.pdf (accessed on 7 October 2020).

23. Russell, S.J.; Peng, K.-W.; Bell, J.C. Oncolytic Virotherapy. Nat. Biotechnol. 2012, 30, 658-670. [CrossRef] [PubMed]

24. Merchan, J.R.; Patel, M.; Cripe, T.P.; Old, M.O.; Strauss, J.F.; Thomassen, A.; Diaz, R.M.; Peng, K.W.; Stephen, J.; Russell, S.J.; et al. Relationship of infusion duration to safety, efficacy, and pharmacodynamics (PD): Second part of a phase I-II study using VSV-IFN $3-N I S$ (VV1) oncolytic virus in patients with refractory solid tumors. J. Clin. Oncol. 2020, 38 (Suppl. 15), 3090. [CrossRef]

25. Tie, Y.; Yang, H.; Zhao, R.; Zheng, H.; Yang, D.; Zhao, J.; Liu, M. Safety and Efficacy of Atezolizumab in the Treatment of Cancers: A Systematic Review and Pooled-Analysis. Drug Des. Devel. Ther. 2019, 13, 523-538. [CrossRef] [PubMed]

26. FDA. Tecentriq ${ }^{\circledR}$. Highlights of Prescribing Information. Available online: https://www.accessdata.fda.gov/drugsatfda_docs/ label/2019/761034s018lbl.pdf (accessed on 7 October 2020).

27. Sharon, E.; Streicher, H.; Goncalves, P.; Chen, H.X. Immune Checkpoint Inhibitors in Clinical Trials. Chin. J. Cancer 2014, 33, 434-444. [CrossRef] [PubMed]

28. FDA. Yervoy®. Highlights of Prescribing Information. Available online: https://www.accessdata.fda.gov/drugsatfda_docs/ label/2018/125377s094lbl.pdf (accessed on 7 October 2020).

29. Curran, M.A.; Montalvo, W.; Yagita, H.; Allison, J.P. PD-1 and CTLA-4 Combination Blockade Expands Infiltrating T Cells and Reduces Regulatory T and Myeloid Cells within B16 Melanoma Tumors. Proc. Natl. Acad. Sci. USA 2010, 107, 4275-4280. [CrossRef]

30. Hellmann, M.D.; Paz-Ares, L.; Bernabe Caro, R.; Zurawski, B.; Kim, S.-W.; Carcereny Costa, E.; Park, K.; Alexandru, A.; Lupinacci, L.; de la Mora Jimenez, E.; et al. Nivolumab plus Ipilimumab in Advanced Non-Small-Cell Lung Cancer. N. Engl. J. Med. 2019, 381, 2020-2031. [CrossRef]

31. Larkin, J.; Chiarion-Sileni, V.; Gonzalez, R.; Grob, J.-J.; Rutkowski, P.; Lao, C.D.; Cowey, C.L.; Schadendorf, D.; Wagstaff, J.; Dummer, R.; et al. Five-Year Survival with Combined Nivolumab and Ipilimumab in Advanced Melanoma. N. Engl. J. Med. 2019, 381, 1535-1546. [CrossRef]

32. Campbell, M.T.; Xie, W.; Shah, A.Y.; Habra, M.A.; Jimenez, C.; Venkatesan, A.M.; Bubley, G.; McKay, R.R.; Choueiri, T.K.; McGregor, B.A.; et al. 986P-Initial Results of a Phase II Study of Nivolumab and Ipilimumab in Metastatic Adrenal Tumours. Ann. Oncol. 2019, 30, v400. [CrossRef]

33. McGregor, B.A.; Campbell, M.T.; Xie, W.; Farah, S.; Bilen, M.A.; Sonpavde, G.; Kilbridge, K.L.; Choudhury, A.D.; Mortazavi, A.; Shah, A.Y.; et al. Phase II Study of Nivolumab and Ipilimumab for Advanced Rare Genitourinary Cancers. JCO 2020, 38 (Suppl. 15), 5018. [CrossRef]

34. Guo, L.; Zhang, H.; Chen, B. Nivolumab as Programmed Death-1 (PD-1) Inhibitor for Targeted Immunotherapy in. J. Cancer 2017, 8, 410-416. [CrossRef]

35. FDA. Opdivo®. Highlights of Prescribing Information. Available online: https://www.accessdata.fda.gov/drugsatfda_docs/ label/2019/125554s070lbl.pdf (accessed on 7 October 2020).

36. Gridelli, C.; Ardizzoni, A.; Barberis, M.; Cappuzzo, F.; Casaluce, F.; Danesi, R.; Troncone, G.; De Marinis, F. Predictive Biomarkers of Immunotherapy for Non-Small Cell Lung Cancer: Results from an Experts Panel Meeting of the Italian Association of Thoracic Oncology. Transl. Lung Cancer Res. 2017, 6, 373-386. [CrossRef] [PubMed]

37. FDA. Ketruda®. Highlights of Prescribing Information. Available online: https://www.accessdata.fda.gov/drugsatfda_docs/ label/2019/125514s040lbl.pdf (accessed on 7 October 2020).

38. Naing, A.; Meric-Bernstam, F.; Stephen, B.; Karp, D.D.; Hajjar, J.; Rodon Ahnert, J.; Piha-Paul, S.A.; Colen, R.R.; Jimenez, C.; Raghav, K.P.; et al. Phase 2 Study of Pembrolizumab in Patients with Advanced Rare Cancers. J. Immunother. Cancer 2020, 8. [CrossRef] [PubMed]

39. Jimenez, C.; Subbiah, V.; Stephen, B.; Ma, J.; Milton, D.; Xu, M.; Zarifa, A.; Akhmedzhanov, F.O.; Tsimberidou, A.; Habra, M.A.; et al. Phase II Clinical Trial of Pembrolizumab in Patients with Progressive Metastatic Pheochromocytomas and Paragangliomas. Cancers 2020, 12, 2307. [CrossRef] [PubMed]

40. Nishino, M.; Tirumani, S.H.; Ramaiya, N.H.; Hodi, F.S. Cancer Immunotherapy and Immune-Related Response Assessment: The Role of Radiologists in the New Arena of Cancer Treatment. Eur. J. Radiol. 2015, 84, 1259-1268. [CrossRef]

41. Tapia, C.; Aung, P.P.; Roy-Chowdhuri, S.; Xu, M.; Ouyang, F.; Alshawa, A.; Hajjar, J.; Singh, G.; Yang, V.; Castillo, L.; et al. Decrease in Tumor Content Assessed in Biopsies Is Associated with Improved Treatment Outcome Response to Pembrolizumab in Patients with Rare Tumors. J. Immunother. Cancer 2020, 8, e000665. [CrossRef]

42. Colen, R.R.; Ahmed, S.; Elshafeey, N.; Karp, D.D.; Pant, S.; Subbiah, V.; Piha-Paul, S.A.; Hong, D.S.; Yap, T.A.; Fu, S.; et al. Radiomics to predict response to pembrolizumab in patients with advanced rare cancers. J. Clin. Oncol. 2020, 38 (Suppl. 5), 66. [CrossRef]

43. Ak, M.; University of Pittsburgh-Hillman Cancer Center, Pittsurgh, PA, USA. Personal communication, September 2020. 
44. Geoerger, B.; Kang, H.J.; Yalon-Oren, M.; Marshall, L.V.; Vezina, C.; Pappo, A.; Laetsch, T.W.; Petrilli, A.S.; Ebinger, M.; Toporski, J.; et al. Pembrolizumab in Paediatric Patients with Advanced Melanoma or a PD-L1-Positive, Advanced, Relapsed, or Refractory Solid Tumour or Lymphoma (KEYNOTE-051): Interim Analysis of an Open-Label, Single-Arm, Phase 1-2 Trial. Lancet Oncol. 2020, 21, 121-133. [CrossRef]

45. FDA. Libtayo®. Highlights of Prescribing Information. Available online: https:/ /www.accessdata.fda.gov/drugsatfda_docs / label/2018/761097s000lbl.pdf (accessed on 7 October 2020).

46. Faiena, I.; Cummings, A.L.; Crosetti, A.M.; Pantuck, A.J.; Chamie, K.; Drakaki, A. Durvalumab: An Investigational Anti-PD-L1 Monoclonal Antibody for the Treatment of Urothelial Carcinoma. Drug Des. Devel. Ther. 2018, 12, 209-215. [CrossRef]

47. FDA. Imfinzi ${ }^{\circledR}$. Highlights of Prescribing Information. Available online: https://www.accessdata.fda.gov/drugsatfda_docs/ label/2018/761069s002lbl.pdf (accessed on 7 October 2020).

48. Sol, B.; de Filette, J.M.K.; Awada, G.; Raeymaeckers, S.; Aspeslagh, S.; Andreescu, C.E.; Neyns, B.; Velkeniers, B. Immune Checkpoint Inhibitor Therapy for ACTH-Secreting Pituitary Carcinoma: A New Emerging Treatment? Eur. J. Endocrinol. 2021, 184, K1-K5. [CrossRef]

49. Klein, O.; Kee, D.; Markman, B.; Michael, M.; Underhill, C.; Carlino, M.S.; Jackett, L.; Lum, C.; Scott, C.; Nagrial, A.; et al. Immunotherapy of Ipilimumab and Nivolumab in Patients with Advanced Neuroendocrine Tumors: A Subgroup Analysis of the CA209-538 Clinical Trial for Rare Cancers. Clin. Cancer Res. 2020, 26, 4454-4459. [CrossRef]

50. Polano, M.; Chierici, M.; Dal Bo, M.; Gentilini, D.; Di Cintio, F.; Baboci, L.; Gibbs, D.L.; Furlanello, C.; Toffoli, G. A Pan-Cancer Approach to Predict Responsiveness to Immune Checkpoint Inhibitors by Machine Learning. Cancers 2019, 11, 1562. [CrossRef] [PubMed]

51. Muenst, S.; Soysal, S.D.; Tzankov, A.; Hoeller, S. The PD-1/PD-L1 Pathway: Biological Background and Clinical Relevance of an Emerging Treatment Target in Immunotherapy. Expert Opin. Ther. Targets 2015, 19, 201-211. [CrossRef] [PubMed]

52. Pillai, S.; Gopalan, V.; Smith, R.A.; Lam, A.K.-Y. Updates on the Genetics and the Clinical Impacts on Phaeochromocytoma and Paraganglioma in the New Era. Crit. Rev. Oncol. Hematol. 2016, 100, 190-208. [CrossRef] [PubMed]

53. Crona, J.; Taïeb, D.; Pacak, K. New Perspectives on Pheochromocytoma and Paraganglioma: Toward a Molecular Classification. Endocr. Rev. 2017, 38, 489-515. [CrossRef] [PubMed]

54. Chouaib, S.; Noman, M.Z.; Kosmatopoulos, K.; Curran, M.A. Hypoxic Stress: Obstacles and Opportunities for Innovative Immunotherapy of Cancer. Oncogene 2017, 36, 439-445. [CrossRef] [PubMed] 